that an injection of antitoxin will prevent an attack of diphtheria with absolute certainty, but it will undoubtedly do so in a large proportion of instances, and, if diphtheria should occur, the attack will in all probability be a mild one. As to what constitutes an efficient dose authorities differ. By some 300 units are considered sufficient, whilst others inject 800 to 1000 units. Our practice in the Ohelmsford and Maldon rural districts has been to give 500 units, and so far with satisfactory results. Such a dose can usually be obtained in a bulk of about 20 minims and a hypodermic syringe may therefore be used for the purpose. With 500 units it is rare to experience any serious after-effects if the injection be made in the loin or between the scapulæ. With larger doses the rash and the joint pains occasionally associated with the use of antitoxin are sometimes met with, their occurrence being dne to the particular batch of serum used and possibly to individual idiosyncrasy. As a rule there is a slight rise of temperature and occasionally a feeling of malaise and nausea within 24 hours of the operation, of ten followed by some irritation round the seat of injection. The first three symptoms quickly pass off, the last may persist for a few days. If, however, the serum be injected into the arm sequelæ are frequent and consist chiefly of inflammation and cedema, together with stiffness of the joints and intense irritation.

It is important to bear in mind that where antitoxin is used as a prophylactic in persons who are actually harbouring the diphtheria bacillus, although the clinical symptoms may be averted, the throats are none the less infective-at all events the bacilli may, in my experience, remain for weeks. Hence such persons are still liable to become foci of infection and should be prevented from spreading the disease until sufficient time has elapsed to eliminate the danger or until they are shown by bacteriological methods to be free from infection.

As a result of my experience detailed above I believe that we possess in antitoxin a valuable means of preventing the onset of diphtheria in persons who have been exposed to infection, and that it is of especial benefit where it is impossible properly to isolate a primary case, or when the infection is introduced into an institution in which a number of susceptible individuals are congregated.

Chelmsford.

\section{THE ROENTGEN RAYS IN SOUTH AFRICA.}

\section{BY J. HALL-EDWARDS, L.R.C.P. EDIN.,}

GURGON RADIOGBAPHER TO THE GENERAL HOSPITAL, BIRMINGHAM, AND TO THE IMPERIAL YEOMANRY HOSPITALS AT DEELFORTEIV AND PRETORIA, SOUTH AFRICA.

AN experience of 14 months as x-ray expert to the Imperial Yeomanry Hospitals at Deelfontein and Pretoria has amply proved the immense usefulness of Roentgen's discovery as applied to military surgery. On starting from England I had already formed some idea as to the extent to which my speciality might be of service, bat my wildest anticipations were exceeded and my preconceived notions born of ignorance, and backed up by the officials at the War office, have proved to be incorrect and absolutely unsatisfactory. On information received from certain pseudo. reliable sources I was convinced that so few bullets found their billets in the tissues of the wounded that an $x$-ray outfit would prove an incumbrance instead of a help, and although I had some hopes that my ideas might prove incorrect I entered upon my task with fear and trembling. These fears were magnified when on reaching Cape Town we were informed that Oronje had been captured and Ladysmith relieved and that the war could not last more than a few weeks. This last statement, like those received at home, was far from true, and whilst it was given in good faith, it was the child of ignorance, born in the oradle manufactured by our Intelligence Department.

I well remember remarking to an officer (on the Government landing-stage at Cape Town), who had been my companion since leaving Fngland and who was wishing me adieu and success, "that if I could take back with me five negatives showing the presence of bullets, I should consider my visit to South Africa more than justified." It would be exceedingly difficult even to guess the percentage of cetained bullets in all gunshot wounds, but there can be no doubt that it is far higher than is generally imagined although taking into consideration the number of wounds received it must be very small. My own figures cannot, of course, be taken as any guide, inasmuch as I only radiographed cases specially sent to me for the purpose, a large majority of the cases admitted to the hospital not being of sufficient interest to warrant the taking of a radiograph. In several of these bullets which could be localised by palpation were removed without the aid of the $x$ rays and they therefore take no part in my calculations. In all, 193 cases of gunshot or shell wounds were submitted to me and in 65 of these there were found and localised, either a whole bullet, portions of a bullet, or fragments of shell. This is, of course, an exceptionally large percentage which can only be accounted for by the assumption that many cases in which the presence of a bullet was suspected were sent to us for the purpose of having them localised. It is absolutely impossible to form any idea of the percentage of retained bullets in wounds received; neither can I satisfy myself as to the range at which most bullets are retained. Bullets which are nearly spent have, of course, the greatest chance of remaining in the tissues, but the ranges given in my notes are so various that many other circumstances must combine to diminish the penetrative power, even at distances where under ordinary conditions they would pass through the body. In previous articles on this subject I have pointed to some of these and a careful perusal of the accompanying table may suggest others.

List of Cases of Injury, with Bullets, Portions of Bullets, and Fragments of Shell, Radiographed at the Imperial Yoemanry Hospitals at Deelfontein and Pretoria, betwoen March 19th, 1900, and March 31st, 1901.

\begin{tabular}{|c|c|c|c|c|c|}
\hline Parts injured. & 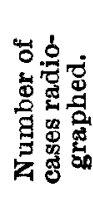 & 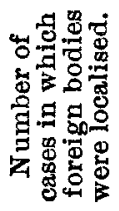 & Parts injured. & 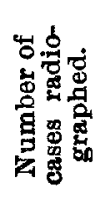 & 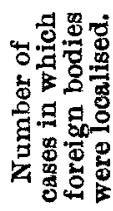 \\
\hline Eye... ... ... & 3 & 1 & Spine $\ldots \ldots$ & 1 & 1 \\
\hline Head $\quad \ldots \quad \ldots$ & 11 & 1 & Back $\quad \ldots \quad \ldots$ & 5 & 3 \\
\hline Neck $\quad \ldots \quad \ldots$ & 2 & 1 & Pelvis ... $\quad .$. & 6 & 4 \\
\hline $\begin{array}{lll}\text { Chest } & \ldots & \ldots\end{array}$ & 18 & 7 & Thigh and & 30 & 18 \\
\hline Shoulder $\quad$... & 10 & 1 & $\begin{array}{llll}\text { hip } & \ldots & \ldots\end{array}$ & $\infty$ & 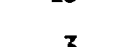 \\
\hline Arm $\quad \ldots \quad \ldots$ & 13 & 4 & $\begin{array}{lll}\text { Knee } & \ldots & \ldots\end{array}$ & 8 & 3 \\
\hline Elbow $\ldots . .$. & 14 & 2 & $\begin{array}{lll}\text { Leg } & \ldots & \ldots\end{array}$ & 16 & 8 \\
\hline Forearm $\quad \ldots$ & 10 & 1 & Ankle $\ldots$ & & 0 \\
\hline $\begin{array}{lll}\text { Wrist } \quad \ldots & \ldots\end{array}$ & 3 & 0 & Foot $\quad \ldots \quad \ldots$ & 18 & 2 \\
\hline Fand $\quad \ldots \quad \ldots$ & 19 & 8 & Total ... ... & 193 & 65 \\
\hline Abdomen ... & 2 & 0 & & & \\
\hline
\end{tabular}

The list here given is not a long one, but is must be remembered that in most of these cases the presence of a foreign body was suspected. Many other cases were examined in order to ascertain the amonnt of injury sustained by bone during the passage of bullets through it, and in addition to several medical cases over 50 accidental fractures were radiographed. Again, during the greater part of our stay in the Karroo we were to all intents and purposes a base hospital, and all the cases had filtered through other hospitals before coming to us. It was only during the last two months that we received any wounded straight from the field, and curiously enough none of these came into my hands.

The list is exceedingly interesting in showing that by far the larger majority of bullets retained in the tissues are found between the ankle and abdomen, whilst the upper extremities are comparatively free, with the exception of the hand. Here only in one instance was a whole bullet retained, the remainder being in the main splinters from bullets which had struck stones in front of the fighting line, and as in most cases the men were lying down the hands and heads were chiefly exposed. Where the head was struck the result was in a very large majority of instances fatal, although a good number of these escaped, as is shown by $m y$ figures. In nearly every instance where a bullet was retained in the hip or thigh the whole of the missile was found. In more than three-fourths of the cases in which foreign bodies were localised they were removed by the operating surgeons and in no single instance was the 
object sought after missed. The position of the builet was marked upon the skin and the depth from the skin was accurately ascertained. The only difficulty that can possibly arise after an exact and carefully made localisation where the bullet is near the bone is (even when the depth from the surface is known) that of deciding whether or not it is embedded in the bone itself. To decide this without preparing a pair of stereoscopic prints one must rely entire upon one's knowledge of anatomy ; not that it is of very great consequence, for having decided that it is better for the patient that the bullet should be removed it is only necessary to be prepared for possibilities. A case in point occurred in a young soldier who was shot in the neighbourhood of the hip-joint. An x-ray localisation showed the bullet apparently lying across the neck of the femur, at the depth of five and a half inches from the buttock. A long consultation failed to show its exact position in relation to the bone, but it was decided to operate. The surgeon cut down upon the spot and found the bullet firmly embedded. It was removed and the patient made a complete recovery. Had it been possible to prepare a pair of pictures which could have been viewed in the reflecting stereoscope the question would have been at once settled, for by this method the exact relations would have been seen. The preparation of such pictures, of course, involves considerable trouble, but I am more than ever convinced that a reflecting stereoscope must in future form part of a base hospital equipment, for although in most cases measurements are amply sufficient there are undoubtedly occasions when it would prove of the greatest possible use.

Localisation by means of the $x$ rays is based upon mathematical calculations and is so absolutely correct that I cannot imagine any surgeon even daring to consider any other method. Yet I am constantly hearing of the telephone probe, the latest competitor in the field of prehistoric instruments which even under the old conditions of warfare were bad, and under the new are worse than useless. There is no position in the body in which a bullet cannot be found and exactly localised by means of the $x$ rays. Moreover, this can be done without disturbing the patient or subjecting him to anything but the slightest inconvenience for at the most 10 minutes. $\mathrm{He}$ runs no risk of infection from dirty probes and the results are absolute. The telephone probe is alone useful for finding a bullet when its position is known, and may on occasion prove of slight assistance during an operation when the bullet is in a difficult position to get at and cannot be seen. I am pleased to say that at The Imperial Yeomanry Hospital the telephone probe was never used, and yet in every instance in which the operating surgeon was called in the bullet was found.

In a previous article published in THE LANCET of Jan. 12th (p. 130) I drew attention to the inefficiency of the $x$-ray arrangements made by the War Office, and it is only since my return home that $I$ have seen the reply of Colonel W. F. Stevenson, R.A.M.C., in which $I$ am pleased to see that he quite agrees with me, that if an $x$-ray specialist is to be of any service he must devote the whole of his time to the subject. As regards the X-ray department which I am informed exists, I would like to ask how it is that experts were not turned out from there? and why it was necessary to employ laymen to do the work? Surely the fact than an expert must spend his whole time at the work should have been recognised years ago. Again, as regards (what I still dare to call) the so-called experts. I have before me three letters from the War Office, dated respectively Oct. 31st, Nov. 23rd, and Dec. 30th, 1899, informing me that experts were not required. Again, late in January, 1900, my services were refused, whilst those of medical students and manufacturers of apparatus were accepted at the princely income of $£ 200$ per annum. I do not wish to argue for one moment that these men have not done good work; but I again say that they can in no way be considered as experts.

I did not say that the apparatus sent out by the War Office was not good or that an insufficient number of sets were supplied, but I know that some of the sets were never used, whilst others were only used occasionally. During the whole of my stay at Deelfontein there was an apparatus at De Aar which I was told on the authority of the principal medical officer was never used. On the occasion of my first visit to Kimberley I found a gentleman in charge who was uninformed as to the use of the localising apparatus; and since then $I$ have received a letter from another gentleman in charge of the same department asking me to give him some instruction. At a large hospital in Pretoria I found the
Mackenzie-Davidson cross-thread localiser was being used as a devoloping table upon which the staff developed their Kodak films and, finally, I left my department at Deelfontein with no one in charge. These facts speak for themselves, and yet $I$ am told that the War Office has a properly equipped $x$-ray department. In laying these facts before the readers of THE LANCET I have no intention of injuring or hurting anyone's feelings, they are written with the hope of bringing about a better order of things; and when the much-talked-of reform in the Army Medical Department is brought about I trust that this most useful adjunct to military surgery will not be forgotten.

That our z-ray department proved a success has already been testified to by our senior surgeon (Mr. A. D. Fripp, O.B.), who in his letters to the medical press has described it as "the most useful dopartment in the hospital" ; and I am sure that Mr. Raymond Johnson, Mr. H. A. Ballance, Mr. William Turner, and Mr. A. P. Parker would admit that some of the best surgery was the outcome of work done there; and I, moreover, feel certain that the figures herein published will go to prove that as an aid and necessity to military surgery the $x$ rays must take the premier position.

Birmingham.

\section{ANEURYSM OF THE SUBCLAVIAN AND AXILLARY ARTERIES: LIGATURE OF THE SECOND PART OF THE SUBCLAVIAN.}

BY G. A. WRIGHT, M.B. OxON., F.R.O.S. ENG.,

SURGKON TO THE MANCHESTER ROYAL INFIRMARY AND PROFHSSOR OY SYSTEMATIO SURGRRY IN OWLNS COLLEGE;

AND

P. R. WRIGLEY, M.R.C.S. ENG., L.R.O.P. LOND., LATE HOUSE SURGKON TO THE MANCHESTER ROYAL INFIRMARY.

A MAN, aged 86 years, was admitted into the Manchester Royal Infirmary on Dec. 12th, 1900, complaining of "swelling of the main artery of the left arm." The appearance of the patient was that of a strong vigorous man, giving no history and presenting no signs of syphilis. His occupation necessitated the occasional lifting of heavy sacks of flour (240 lb.). He told us that in May, 1900, he first noticed pain in the left shoulder over the acromion, which was worse in the evening than on rising in the morning. He had the shoulder rubbed and as the pain disappeared entirely in two or three weeks he thought no more of it until in September the pain returned in greater severity. At first the trouble was looked upon as rheumatic, but in December the presence of aneurysm was recognised and he was sent to the infirmary.

On admission on Dec. 12th, the patient complained of pain in the left acromial region shooting down the arm into the left breast and the back of the neck. On examination there was found to be no difference in the muscular power of the two arms and hands and there was neither wasting nor codema of the left hand and arm. Sensation, too, was quite normal. In the left clavicular region there was an extensive swelling stretching some distance above and below the clavicle and so prominent that the outer two-thirds of the clavicle were not apparent on inspection. Pulsation could be observed over the whole swelling. On palpation the swelling was found to be more extensive below than above the clavicle and to be both expansile and pulsatile. The swelling could be grasped by one hand just beneath the clavicle with the other pressing deeply in the axilla when the expansile pulsation could be felt in the axilla, which could also be felt in the posterior triangle of the neck. On compressing the third part of the subclavian artery between the finger and the first rib puisation in the tumour was completely stopped, but the artery in its third part was evidently dilated. On percussion there was a dull area on the left side of the chest extending from the clavicle to one and a half inches below it and from the anterior axillary fold to within three and a half inches of the middle line of the body. On auscultation a harsh systolic bruit could be heard.

An operation was performed on Dec. 19th. The patient 